\title{
Temporal Dynamics and Spatial Distribution of Water Pollution Footprint in Jiangxi Province from 2004 to 2015
}

\author{
Qiugen Zhang ${ }^{1, a}$, Yuqiong Huang ${ }^{1, b}$, Shifeng Wang ${ }^{2, c}$, Suhua Chen ${ }^{1, d}$ \\ ${ }^{1}$ School of Environment and Chemistry Engineering, Nanchang Hangkong University, 330063, \\ Nanchang, Jiangxi, PRC; \\ ${ }^{2}$ Environmental Engineering Assessment Center, Environmental Protection Department of Jiangxi \\ Province, 330077, Nanchang, Jiangxi, PRC \\ a904644628@qq.com, b1143327024@qq.com, 526147541@qq.com, [690122337@qq.com
}

\begin{abstract}
Keywords: Pollution Footprint; Water Pollutant; Water Pollution Capacity; Temporal Dynamics; Spatial Distribution; Jiangxi Province.

Abstract. Based on the connotation of pollution footprint and the index model of water pollution which guided by ecological footprint theory, the water pollution footprint of Jiangxi province from 2004 to 2015 was calculated according to the survey of water pollutant emission statistics. Temporal dynamics and spatial distribution of water pollution footprint were analyzed. The results showed that the water pollution footprint of Jiangxi province was rose from $414797.83 \mathrm{hm}^{2}$ in 2004 to $548350.61 \mathrm{hm}^{2}$ in 2015 . The pollution footprints of COD and $\mathrm{NH}_{3}-\mathrm{N}$ were separately increased form $233598.73 \mathrm{hm}^{2}$ and $181199.10 \mathrm{hm}^{2}$ in 2004 to $261799.91 \mathrm{hm}^{2}$ and $286550.69 \mathrm{hm}^{2}$ in 2015 . The water pollution footprints of Ganzhou and Shangrao were relatively large while the water pollution footprint of Yingtan and Xinyu was relatively small in Jiangxi 11 cities. The water pollution capacities of Jiangxi province and 11 cities were showed a general upward trend during in 2004-2015. And the water pollution capacities of Jiujiang and Shangrao were relatively large while the water pollution carrying capacities of Pingxiang, Jingdezhen and Yingtan were relatively small. Jiangxi province and 11 cities appeared water pollution deficit in 2004-2015. The water pollution deficits of Ganzhou and Shangrao were relatively large while the water pollution deficits of Yingtan and Xinyu were relatively small.
\end{abstract}

\section{Introduction}

In 1987, the world environmental development committee first proposed a new concept and development model, which was the sustainable development of the environment. Since then, the evaluation of regional ecological system had become the forefront and hotspot of sustainable development research. In order to evaluate the sustainable development more intuitive and accurate, many scholars at home and abroad had put forward the evaluation methods of sustainable development, and the ecological footprint method was one of the most widely used to measure the extent of sustainable development. The ecological footprint was first proposed by the Canadian ecological economist WilliamRees in $1992^{[1]}$, and developed into the ecological footprint model which was a new way to measure the pressure and influence of human activities on ecological system by his doctoral student Wackernagel in $1996^{[2]}$.

In order to overcome the limitations of the traditional ecological footprint theory to estimate the limitation of the ecological footprint that needed for the degradation of pollutants, so some scholars had put forward the pollution footprint. Pollution footprint was a kind of ecological footprint based on environmental pollutants absorb, which was a typical ecological footprint based on ecosystem service. The pollution footprint which could include most of the pollutants produced by human activities according to different category or types of pollutants to refine ${ }^{[3]}$. It was not a simple replacement for the traditional ecological footprint.

With the rapid development of industrialization and urbanization in Jiangxi province and the rapid growth of population, the problems of ecological environment were becoming more and more prominent, and the regional ecological environment and economic development were not coordinated. It affected the sustainable development of social economy in Jiangxi province. The dynamic study of 
water pollution footprints in Jiangxi province was rare at present. Based on the connotation of pollution footprint and the model of atmospheric pollution, the temporal dynamics and spatial distribution of Jiangxi province water pollution footprint were calculated and analyzed from 2004 to 2015 by choosing the $\mathrm{COD}$ and $\mathrm{NH}_{3}-\mathrm{N}$ water pollutants. It was very benefit to provide scientific basis for the development of water environment policy and water pollution prevention, and it was also benefit to promote the sustainable development of water environment in Jiangxi province.

\section{Theoretical Connotation of Pollution Footprint}

Pollution footprint originates from ecological footprint. Pollution footprint theory and model were produced based on ecological service function of pollutant absorption according to the ecological footprint comprehensive calculation model and the measure model of ecological capacity ${ }^{[4]}$. Human discharge all kinds of pollutants which need to adsorbed and degrade through the pollutant capacity of ecological system while human consume various products and resources. The sewage services of the ecosystem turns into the area of the bio-productive land at last. The pollution footprint theory could comprehensively reflect the impact of human production and life on the ecological system, which included not only energy combustion produce all kinds of greenhouse gases and pollutants, but also a variety of pollutants produced by human activities ${ }^{[5]}$. The adsorption and degradation processes of different pollutants in the ecosystem were different, and the effects of different types of pollutants on the ecosystem could have overlapping effects. Therefore, the corresponding pollution footprint model should be constructed according to the specific types of pollutants ${ }^{[4]}$. The pollution footprint could be divided into two categories. When different pollutants had obvious overlapping impact on the ecological environment, it should select a maximum of these pollutants pollution footprint as this type of pollution footprint. When different pollutants hadn't obvious overlapping impact on the ecological environment, the total footprint of these pollutants should be selected as the pollution footprint of the pollutants.

In addition, pollution footprint model also included the pollution capacity which referred to the total land area that could absorb the pollutants produced by human activities ${ }^{[4]}$. It also represented the ecological system assimilative capacity.

The equilibrium factor and yield factor should be used to calculate the pollution footprint and the pollution capacity. The equilibrium factor referred to the ratio of the average capacity of certain type of land to the average capacity of all land types in the world. And the yield factor referred to the ratio of the average absorption capacity of certain types of land in a certain region to the average level of the world.

\section{The General Situation of Jiangxi}

Jiangxi is located on the south bank of the middle and lower reaches of the Yangtze River, in north latitude $24^{\circ} 29^{\prime}$ to $30^{\circ} 04^{\prime}$, east longitude $113^{\circ} 34^{\prime}$ to $118^{\circ} 28^{\prime}$. The east, south and west sides of Jiangxi province are surrounded by mountains. From outer to inner, from south to north, the whole terrain tilts gradually to Poyang Lake and forms a huge basin opened to the north. Jiangxi covers a land area of $166900 \mathrm{~km}^{2}$ with main mountainous and hilly. The mountainous area is about $36 \%$ of the province's total area, and hills accounts for $42 \%$, the others are about $22 \%$. There are more than 2400 rivers in Jiangxi, the main rivers includes the Ganjiang River, Fuhe River, Xinjiang River, Xiushui River, Raohe River. All river flow to Poyang Lake and then flow into the Yangtze River. Ganjiang river is the largest river of Jiangxi province and the second largest tributary of the Yangtze river. Poyang Lake is the largest freshwater lake in China. Jiangxi has the characteristics of subtropical humid climate which includes four seasons distinct, warm climate, abundant sunshine, abundant rainfall and long frost free period. Jiangxi had an excellent ecological environment, and the forest coverage rate reached $63.1 \%$. But environmental pollution emissions were high, $\mathrm{COD}$ was $396540.47 \mathrm{t}, \mathrm{NH}_{3}-\mathrm{N}$ was $47347.10 \mathrm{t}, \mathrm{SO}_{2}$ was 528052.69t, NOx was 283281.11t, and smoke (powder) dust was 454902.95t in 2015, which 
respectively accounted on the whole nation $1.78 \%, 2.06 \%, 2.84 \%, 1.53 \%$ and $2.96 \%$. Environmental pollution in Jiangxi would affect the sustainable development of the province.

\section{Data Source and Research Method}

Data Source.The data used in the ecological footprint calculation model was taken from Jiangxi Statistical Yearbook 2005-2016 ${ }^{[6]}$, Jiangxi Statistical Annual Report and relevant reference literature.

Research Method.The pollution footprint and the pollution capacity were calculated though applying the pollution footprint model. Based on the calculation results, the environmental sustainability of Jiangxi province was analyzed and assessed.

(1)Water pollution footprint. The major water pollutants $\mathrm{COD}$ and $\mathrm{NH}_{3}-\mathrm{N}$ were Choose to calculate its pollution footprint. The calculation method was shown in Equation (1) and Equation (2).
$\mathrm{PF}_{\mathrm{COD}}=\mathrm{EQF}_{\mathrm{COD}} \times \mathrm{YF}_{\mathrm{COD}} \times \mathrm{P}_{\mathrm{COD}} /\left(\mathrm{NY}_{\mathrm{COD}}\right)$
$\mathrm{PF}_{\mathrm{NH} 3-\mathrm{N}}=\mathrm{EQF}_{\mathrm{NH} 3-\mathrm{N}} \times \mathrm{YF}_{\mathrm{NH} 3-\mathrm{N}} \times \mathrm{P}_{\mathrm{NH} 3-\mathrm{N}} /\left(\mathrm{NY}_{\mathrm{NH} 3-\mathrm{N}}\right)$

In the Equation: $\mathrm{PF}_{\mathrm{COD}}$ and $\mathrm{PF}_{\mathrm{NH} 3-\mathrm{N}}$ separately represented the pollution footprint $\left(\mathrm{hm}^{2}\right)$ of $\mathrm{COD}$ and $\mathrm{NH}_{3}-\mathrm{N} ; \mathrm{EQF}_{\mathrm{COD}}$ and $\mathrm{EQF}_{\mathrm{NH} 3-\mathrm{N}}$ separately represented the equilibrium factor of COD and $\mathrm{NH}_{3}-\mathrm{N}$; $\mathrm{YF}_{\mathrm{COD}}$ and $\mathrm{YF}_{\mathrm{NH} 3-\mathrm{N}}$ separately represented the production factor of $\mathrm{COD}$ and $\mathrm{NH}_{3}-\mathrm{N} ; \mathrm{P}_{\mathrm{COD}}$ and $\mathrm{P}_{\mathrm{NH} 3-\mathrm{N}}$ separately represented the total emission(t) of $\mathrm{COD}$ and $\mathrm{NH}_{3}-\mathrm{N}$; $\mathrm{NY}_{\mathrm{COD}}$ and $\mathrm{NY}_{\mathrm{NH} 3-\mathrm{N}}$ separately represented the average absorptive capability $\left(\mathrm{kg} / \mathrm{hm}^{2}\right)$ of COD and $\mathrm{NH}_{3}-\mathrm{N}$.

(2)Water Pollution Capacity. The calculation method of water pollution capacity was shown in Equation (3).

$$
P C=\sum_{k=1}^{n} P C k=\sum_{k=1}^{n} \sum_{j=1}^{n}(A j \cdot Y F j \cdot E Q F j)
$$

In the Equation: $\mathrm{PC}$ represented the total water pollution capacity $\left(\mathrm{hm}^{2}\right) ; P C_{k}$ represented the pollution capacity $\left(\mathrm{hm}^{2)}\right.$ of the k-type water pollutants; $A_{j}$ represented the area $\left(\mathrm{hm}^{2}\right)$ of the j-type of land that absorbed the k-type water pollutants; $Y F_{j}$ represented the production factor; $E Q F_{j}$ represented the balance factor.

(3) Water Pollution Deficit or Surplus.Water pollution deficit or surplus referred to the value of water pollution footprint reducing the capacity of water pollution, it was shown in Equation (4).

$E_{p}=P F-P C$

In the Equation: $E p$ represented water pollution deficit or surplus( $\left(\mathrm{hm}^{2}\right), P F$ and $P C$ separately represented the water pollution footprint and the water pollution capacity. It was the pollution deficit when the water pollution footprint was greater than the water pollution capacity. While the opposite was the water pollution surplus.

\section{Results and Analysis}

Water pollution footprint in Jiangxi province from 2004 to 2015 . The average assimilative capacity of COD and $\mathrm{NH}_{3} \mathrm{~N}$ was respectively $1514.67 \mathrm{~kg} / \mathrm{hm}^{2}$ and $153.47 \mathrm{~kg} / \mathrm{hm}^{2[7]}$. The pollution footprint of COD and $\mathrm{NH}_{3} \mathrm{~N}$ in the land and Jiangxi province from 2004 to 2015 were calculated according to Equation (1) and Equation (2). there were shown in figure 1 to figure 3.

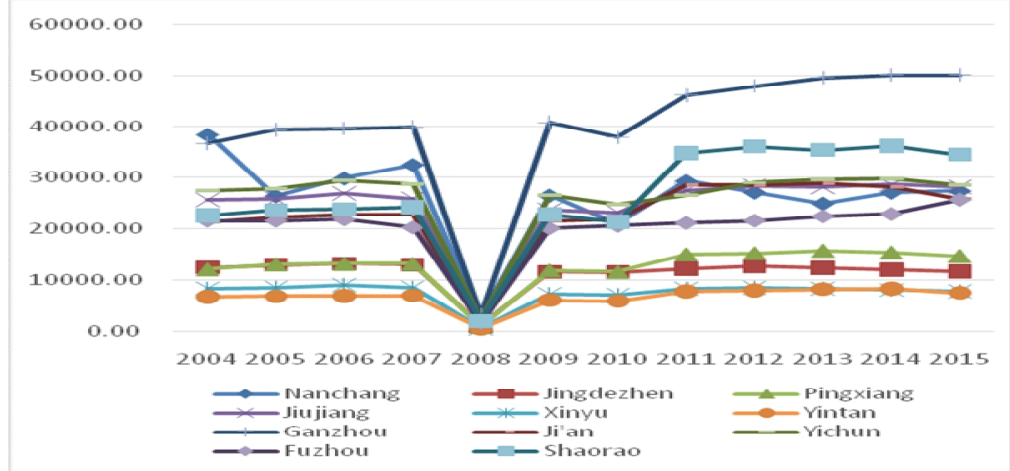

Fig.1 the COD pollution footprint of 11 cities in Jiangxi province during in 2004-2015 
The fig. 1 was shown that the COD pollution footprint of Ganzhou and Shangrao were relatively large while the COD pollution footprint of Yingtan and Xinyu were relatively small in Jiangxi 11 cities. The pollution footprint of COD in the 11 cities decreased significantly in 2008, it may be affected by the 2008 financial crisis which led to a dramatic decline in industrial productivity and people's living standards. So wastewater and water pollutant emissions dropped significantly. As the effects of the financial crisis receded, industrial productivity and people's living standards gradually improved, emissions of wastewater and water pollutants were beginning to increase. So the COD pollution footprint of 11 cities was on a slow upward trend from 2009 to 2015.

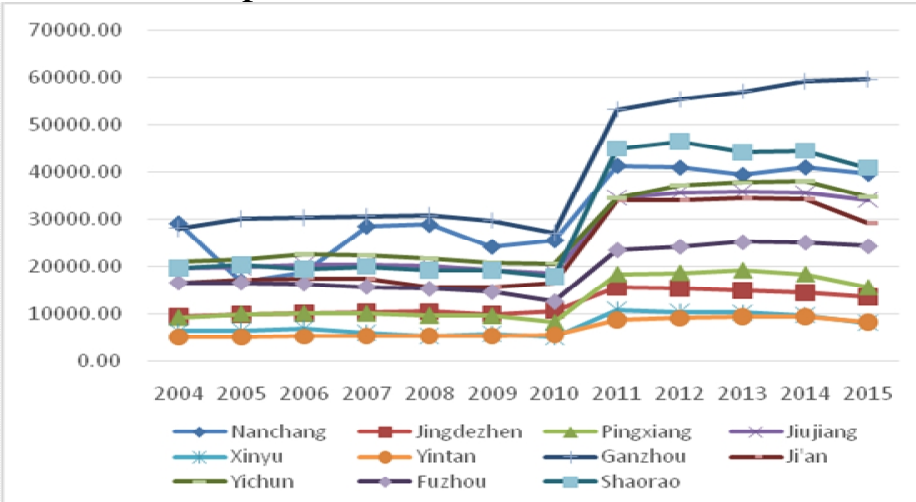

Fig. 2 the $\mathrm{NH}_{3}-\mathrm{N}$ pollution footprint of 11 cities in Jiangxi province during in 2004-2015

The fig. 2 was shown that the $\mathrm{NH}_{3}-\mathrm{H}$ pollution footprint of Ganzhou, Shangrao and Nanchan were relatively large while the $\mathrm{NH}_{3}-\mathrm{H}$ pollution footprint of Yingtan and Xinyu were relatively small in Jiangxi 11 cities. It may be related to the local population and industrial development level. The population of Nanchan, Ganzhou and Shangrao were relatively large and industry was relatively developed while the population of Yingtan and Xinyu were relatively small. There was a significant increasing trend of $\mathrm{NH}_{3} \mathrm{~N}$ pollution footprint in 11 cities from 2010 to 2011, while there was a slow downward trend from 2014 to 2015.

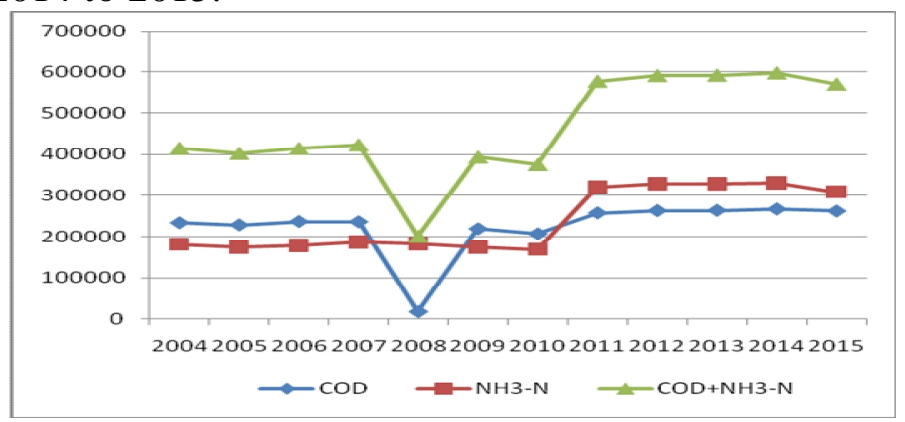

Fig.3 The water pollution footprint of Jiangxi province during in 2004-2015

The fig. 3 was shown that the 2008 financial crisis seriously affected the COD pollution footprint, which led to a significant drop of the water pollution footprint in Jiangxi in 2008. In order to get rid of the impact of the financial crisis, the government introduced the stimulus policies to speed up economic recovery industrial production. In this way, the water pollution footprint of Jiangxi province elevated in 2009 and remained high in 2011-2015.

The proportion of COD and $\mathrm{NH}_{3}-\mathrm{N}$ pollution footprint had little difference. Before 2011, COD pollution footprint was greater than $\mathrm{NH}_{3}-\mathrm{N}$ pollution footprint, and after 2011, COD pollution footprint was less than $\mathrm{NH}_{3}-\mathrm{N}$ pollution footprint. Except for 2008, the water pollution footprint of Jiangxi remained stable and declined slightly from $414797.83 \mathrm{hm}^{2}$ in 2004 to $375579.19 \mathrm{hm}^{2}$ in 2010 . But during in 2010-2011, Jiangxi water pollution footprint increased significantly from $577141.06 \mathrm{hm}^{2}$ in 2011 to $548350.61 \mathrm{hm}^{2}$ in 2015 . The largest water pollution footprint of Jiangxi was $597018.01 \mathrm{hm}^{2}$ in 2014, and the minimum was $201259.84 \mathrm{hm}^{2}$ in 2008. The pollution footprint of COD and $\mathrm{NH}_{3}-\mathrm{N}$ was separately increased form $233598.73 \mathrm{hm}^{2}$ and $181199.10 \mathrm{hm}^{2}$ in 2004 to $261799.91 \mathrm{hm}^{2}$ and $286550.69 \mathrm{hm}^{2}$ in 2015 . The water pollution footprint of Ganzhou and Shangrao was relatively large while the water pollution footprint of Yingtan and Xinyu was relatively small in Jiangxi 11 cities. 
Water pollution capacity in Jiangxi province from 2004 to 2015. The equilibrium factor and yield factor of the water in Equation (3) was 0.2 and 1.0 respectively ${ }^{[7]}$, the water pollution capacities of Jiangxi province and 11 cities in 2004-2015 years were calculated and shown in figure 4.

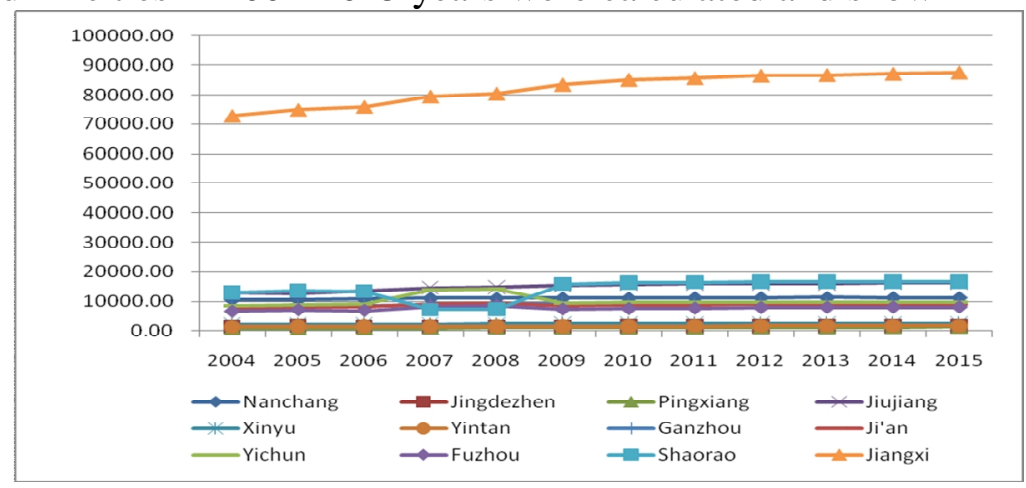

Fig.4 The water pollution carrying capacity of Jiangxi and 11 cities in 2004-2015

The results showed that the water pollution capacities of Jiangxi province and 11 cities were shown a general upward trend in 2004-2015. And the water pollution capacity of Jiangxi province increased from $72766.20 \mathrm{hm}^{2}$ in 2004 to $86722.56 \mathrm{hm}^{2}$ in 2015 . The water pollution capacity of Pingxiang, Jingdezhen and Yingtan was relatively small while the water pollution capacity of Jiujiang and Shangrao was relatively large.

Water pollution deficit of Jiangxi province from 2004 to 2015. According to Equation (4), the water pollution deficit of Jiangxi province and 11 cities in 2004-2015 years was calculated and shown in figure 5.

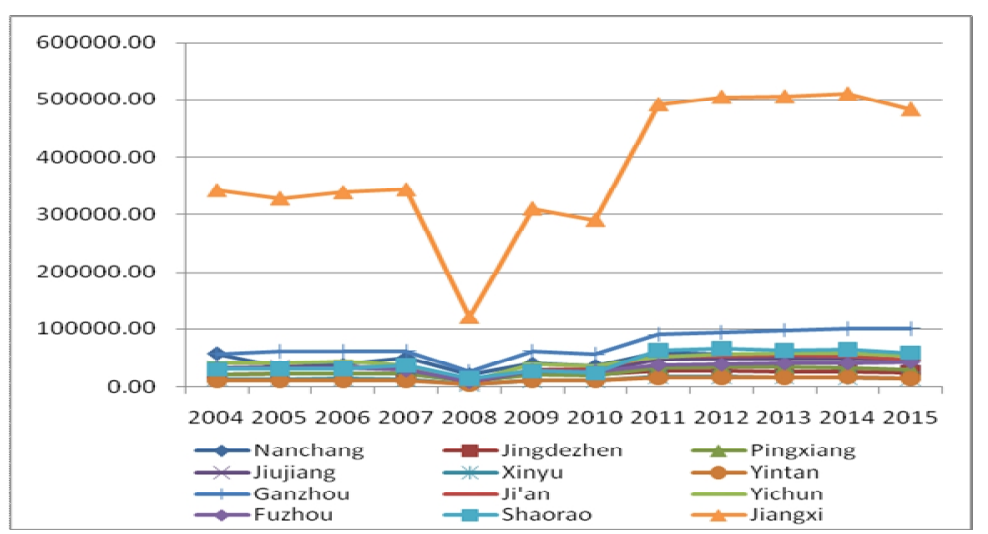

Fig.5 The water pollution deficit of Jiangxi province and 11 cities in 2004-2015

According to fig.5, Jiangxi province and 11 cities in 2004-2015 all appeared water pollution deficit that indicated the water environment capacity of Jiangxi province was not enough to absorb water pollutants which will lead to deterioration of water environment quality.

The water pollution deficit of Yingtan and Xinyu was relatively small, and the water pollution deficit of Ganzhou and Shangrao was relatively large. The pollution footprint of $\mathrm{NH}_{3}-\mathrm{N}$ in Jiangxi province changed little in 2004-2015. The water pollution deficit in Jiangxi decreased sharply in 2008 that mainly was consistent with the temporal dynamic trend of COD pollution footprint.

\section{Conclusion}

Except for the year of the financial crisis in 2008, the contradiction was becoming more and more acute between the rising of water pollution footprint and the sustainable development of water environment in Jiangxi province in the 21st century. Based on the pollution footprint model, the temporal and spatial distribution of water pollution footprint in Jiangxi province was studied. In the past 2004-2015 years, Jiangxi province showed a water pollution deficit and a increasing trend year by year. In order to promote the sustainable improvement of water environment in Jiangxi, it was necessary to vigorously develop ecological industry and build environment-friendly and water-saving clean enterprises, so as to improve water recycling efficiency and reuse rate, and reduce water pollutant emissions. Secondly, in order to improve the water environment capacity, the water area should be protected and the water 
system should be comprehensively renovated. At last, in order to ensure all types of enterprises and institutions discharging sewage according with them pollutant discharging license and them gross control indicator, a sound and strict environmental administrative supervision system should be established and strictly implemented.

\section{Acknowledgement}

This study was financially supported by the science and technology project of Jiangxi Education Department (GJJ150741).

\section{References}

[1] Rees W E: Environment and Urbanization Vol. 4(1992), p. 120

[2] Wackernagel M, Rees W E: Our Ecological Footprint: Reducing Human Impact on the Earth. New Society, Gabrioala, B C, Canada, 1996

[3]Jiao W J, Min Q W, Cheng S K, et al: Acta Ecologica Sinica(in Chinese), Vol. 31(2011), p.5599

[4]Zhao H X, Xu S J. Journal of South China Normal University(Natural Science Edition,in Chinese), Vol. 47(2015),p.116

[5]Zhou T, Wang Y P, Gong J Z, et al: Acta Ecologica Sinica(in Chinese), 35(2015), p.4592

[6] Jiangxi Bureau of Statistics: Jiangxi Statistical Yearbook (2004-2015). China Statistics Publishers (2004-2015)

[7]Wu J , Meng W, Wu M Z, et al: Henan Science(in Chinese),, Vol. 25(2007), p.1063 